\title{
Filling in the Surgical Safety Checklist in Brazilian hospitals
}

\author{
Preenchimento da Lista de Verificação de Segurança Cirúrgica em hospitais brasileiros
}

Raquel Elisa de Almeida ${ }^{1}$, Maria Cristina Soares Rodrigues ${ }^{1}$

Objective: analyzing the scientific evidence about the frequency of checking items on the Surgical Safety Checklist in Brazilian hospitals. Methods: integrative review. The databases used: Latin American and Caribbean Literature in Health Sciences, Medical Literature Analysis and Retrieve System Online, Spanish Librarian Index of Health Sciences, Nursing Database, National Medical Sciences Information Center of Cuba, Cochrane Library and Cumulative Index to Nursing and Allied Health Literature. The search occurred in January 2018, combining the descriptors: patient safety, surgical centers, surgical rooms, operative surgical procedures and checklist. Results: in spite of the great variation of the frequency of the items checking, the majority presented low gauging, with an average lower than $80.0 \%$. The best verification was observed in the first stage of the instrument. Conclusion: the frequency of the checking was unsatisfactory, evincing the need for improvements, based on the safety culture of the surgical patient.

Descriptors: Patient Safety; Surgicenters; Checklist; Guideline Adherence.

Objetivo: analisar as evidências científicas acerca da frequência de checagem de itens da Lista de Verificação de Segurança Cirúrgica em hospitais brasileiros. Métodos: revisão integrativa. Utilizaram-se as bases de dados: Literatura Latino-Americana e do Caribe em Ciências da Saúde, Medical Literature Analysis and Retrievel System Online, Índice Bibliotecário Español de Ciencias de La Salud, Base de Dados em Enfermagem, Centro Nacional de Informação de Ciências Médicas de Cuba, Cochrane Library e Cummulative Index to Nursing and Allied Health Literature. A busca ocorreu em janeiro de 2018, combinando-se os descritores: segurança do paciente, centros cirúrgicos, salas cirúrgicas, procedimentos cirúrgicos operatórios e checklist. Resultados: apesar da grande variação da frequência de checagem dos itens, a maioria apresentou baixa aferição, com média menor que 80,0\%. Melhor verificação foi observada na primeira etapa do instrumento. Conclusão: a frequência de checagem mostrou-se insatisfatória, evidenciando necessidade de melhorias, alicerçadas na cultura de segurança do paciente cirúrgico.

Descritores: Segurança do Paciente; Centros Cirúrgicos; Lista de Checagem; Fidelidade a Diretrizes.

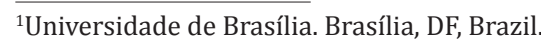

Correspondent author: Raquel Elisa de Almeida

SGCV lote 27/30, Torre C, apartamento 209, Guará - Zona Industrial, CEP: 71215-770. Brasília, DF, Brazil. E-mail: qquel_aps@hotmail.com 


\section{Introduction}

With the advancement of scientific knowledge and technologies, health care has became more complex, more effective, but less secure ${ }^{(1)}$. The patient safety gained prominence from the year 2000 with the release of the report "To err is human", published by the Institute of Medicine that brought adverse events as a quality problem related to patient safety ${ }^{(1-2)}$.

In order to reducing risks and preventing adverse events, the World Health Organization has directed actions to the so-called global challenges, in particular to promote safer surgery, and in 2004 created the Patient Safety Program ${ }^{(1)}$.

About $14.0 \%$ of surgical patients suffer some type of damage ${ }^{(3)}$. In Brazil, avoidable adverse events more frequent in hospitalized patients are related to surgery and/or anesthesia ${ }^{(4)}$. Considering that nearly seven million surgical patients suffer complications each year and one million die during or immediately after surgery, surgical safety has emerged as a worldwide public health concern ${ }^{(5)}$.

In 2009, the Brazilian Health Ministry released the Safe Surgeries Manual, which directs attention to prevention of surgical site infection, safe anesthesia, safe surgical teams and indicators of surgical care ${ }^{(5)}$.

In 2013, the Brazilian Health Ministry instituted the National Patient Safety Program and, in the same year, the National Health Surveillance Agency established that the patient safety plan in health services should create risk management strategies, to other issues, promote safe surgeries ${ }^{(6-7)}$. Also, in 2013, the Protocol for Safe Surgery was launched, which establishes the systematic use of the Safe Surgery Checklist as a strategy to reduce risks of surgical incidents, reinforce safety practices, promote teamwork and improve communication between the surgical team ${ }^{(8)}$.

The "entry" or sign in of the list is essential so that the staff does not operate the wrong patient or surgical site or performs the procedure improperly. In this moment, the patient identification, the consent for surgery, the surgical site demarcation, the anesthesia safety, the pulse oximeter, the patient allergies, the airway assessment and the risk of blood loss are then checked. In the "surgical pause" or time out, team members introduce themselves, confirm the patient's name, the proposed surgery and the surgical site, there is a breath discussion about the expected critical events and the operative planning, they verify the sterilization of the materials and confirm the antibiotic prophylaxis and the presence of necessary imaging tests. The "exit" or sign out is performed before the patient leaves the room, when the instrument counting is confirmed, the compresses and needles, the correct identification of pathological samples, the problems with equipment and if there are complications that may influence the recovery of the patient and demand specific care $\mathrm{e}^{(5,8)}$.

It is known that the use of the checklist potentiates the prevention of deaths related to surgical procedures and reduces postoperative mortality by $22.0 \%{ }^{(9)}$. The reduction of adverse events is related to a culture focused on well-established patient safety, being the great challenge of the Safe Surgeries Saves Lives campaign ${ }^{(10)}$.

The introduction of the checklist in the routine of a surgical center is a step towards a culture of surgical safety. It is necessary to understand its importance, knowledge and involvement of all team members, so that the process is incorporated into daily practice and becomes effective $\mathrm{e}^{(5,11)}$.

Therefore, the present study was guided by the following question: what is the frequency of checking the items of the Surgical Safety Checklist in Brazil? In order to know this panorama, the aim of the study was to analyze in the scientific productions the frequency of checking the items of the Surgical Safety Checklist by surgical teams in Brazilian hospitals.

When performing an integrative review on the subject, the knowledge of the Brazilian reality about the use of the checklist is revealed. The complete filling of the instrument is recommended by the World Health Organization in order to guarantee confirmation of all the determinants of safe surgery ${ }^{(5)}$. In view 
of the apprehension of the weaknesses related to the incompleteness of the list, it is hoped to base the delineation of specific strategies aimed at improving the surgical safety process. In view of this, the study aimed to analyze the scientific evidence about the frequency of checking items on the Surgical Safety Checklist in Brazilian hospitals.

\section{Methods}

Integrative literature review, carried out through the search, critical evaluation and synthesis of relevant scientific researches, produced on the subject, for quick access to the results of studies that support decision-making in professional practice ${ }^{(12)}$.

Based on the definition of the research question and the purpose of the study, in order to identify the published studies on the subject, an online search was conducted in January 2018 in the Latin American and Caribbean Literature in Health Sciences databases (LILACS), Medical Literature Analysis and Retrieval System Online (MEDLINE/PubMed), Spanish Librarian Index of Health Sciences (IBECS), Nursing Database (BDENF), National Information Center of Medical Sciences of Cuba (CUMED), Cochrane Library and Cumulative Index to Nursing and Allied Health Literature (CINAHL).

Original articles were included in the study, which included a checklist of the World Health Organization's safe surgery checklist or adaptation to Brazilian hospitals, indexed in the referred databases, published from January 2009 to December 2017, that is, from of the year of introduction of the Safe Surgery Program in Brazil, with a summary and full texts available free of charge for analysis, in Portuguese, English or Spanish languages, and containing in the title, abstract and/or subject the following combination of Descriptors in Health Sciences(DeCS): "Patient Safety" AND ("surgicenters" OR "Operating rooms" OR "Surgical Procedures, Operative") AND "checklist". Case reports, literature reviews, experience reports, expert opinions and articles on checklist adherence in countries other than Brazil were excluded. Duplicate articles in databases were considered only once.

To select the articles, the guideline used was PRISMA, composed of four phases: identification, selection, eligibility and inclusion ${ }^{(13)}$. With the use of established DeCS, 365 studies were identified. Refining the search from the availability of the full text for reading and the period of publication and delimited languages, 274 articles were selected. It was proceeded careful reading of the titles and abstracts, being 27 eligible for full reading because they attend the theme of the study. Among the full text articles read, five contemplated the other inclusion criteria, if they were original studies that portrayed the checklist items check, in Brazilian hospitals. These five papers were included for analysis in this integrative review.

The selected studies had the data extracted, organized and summarized. The level of evidence was assessed in order to strengthen the conclusions generated on the subject under investigation ${ }^{(12)}$. The evidence was classified according to the research design: Level I-systematic review of controlled and randomized clinical trials; Level II-randomized controlled clinical trial; Level III.1-controlled clinical trial without randomization; Level III.2-cohort study, case-control or analytical; Level III.3-multiple time series, with or without intervention, or uncontrolled experimental studies; Level IV-authorities' opinion, descriptive studies, or expert report ${ }^{(14)}$.

The data were analyzed with a quantitative approach, by measuring the frequency of checking each of the items in the Safe Surgery checklist adopted in the service.

\section{Results}

Five articles were included for analysis in this integrative review, which two were located in the LILACS database and three in MEDLINE. The studies analyzed were published between 2014 and 2016, 
one based on documentary research that analyzed 25 checklists and 12,629 items, and four, observational studies, with a sample ranging from 20 to 1,052 surgeries. In all, the five articles have level IV of evidence, being descriptive studies and presenting a quantitative approach. Synthetically, the researches were aimed at analyzing the checklist of the study scenarios and evaluating the registration of items and adherence to the instrument ${ }^{(15-19)}$.

The results of the articles showed noncompliance in the completion of the checklist, through non-application in the totality of surgeries, incompleteness of the instruments, non-verbal verification of different items, not guarantee of safety to the surgical patient, besides communication failure between the surgical teams ${ }^{(15-19)}$.

In conclusion, the studies mentioned that adherence to the checklist is insufficient, with great variety among the items. When good adherence was reported, the completeness of the checks was reinforced. It was inferred that, the failure to meet the objectives of the Safe Surgery Program, the surgical team's neglect of the process, and the need for immediate adjustments, with more structured methods of implementation, training and motivation of the team ${ }^{(15-19)}$.

The articles mentioned that the checklists used in the hospitals studied were adapted to local reality, based on the proposal of the World Health Organization. In this way, the items analyzed varied among the studies. We used the frequency of checking each of the items of the three steps of the list presented in each study to calculate the mean and standard deviation of the check. The study that did not mention the conference of an item, because it was not present in the checklist used, was excluded from the calculation of the average. The results are shown in Tables 1,2 and 3.

Table 1 - Distribution of the relative frequency, mean and standard deviation of the check of the Sign In items of the Surgical Safety Checklist

\begin{tabular}{|c|c|c|c|c|c|c|c|}
\hline \multirow{2}{*}{ Items } & \multicolumn{5}{|c|}{ Articles } & \multirow{2}{*}{ Mean (\%) } & \multirow{2}{*}{$\begin{array}{l}\text { Standard } \\
\text { Deviation }\end{array}$} \\
\hline & $1(\%)$ & $2(\%)$ & $3(\%)$ & $4(\%)$ & $5(\%)$ & & \\
\hline Patient identification & 10.0 & 90.1 & 95.0 & 99.6 & 94.0 & 77.7 & 38.0 \\
\hline Pre-anesthetic evaluation & - & - & - & 93.8 & 6.0 & 49.9 & 52.5 \\
\hline Consent for surgery & 0.0 & - & 100.0 & 96.5 & 94.0 & 72.6 & 48.5 \\
\hline Consent for anesthesia & 0.0 & - & 100.0 & 90.0 & 94.0 & 71.0 & 47.5 \\
\hline Confirmation of the procedure & - & - & 95.0 & - & - & 95.0 & -- \\
\hline Confirmation of surgical site & - & - & 95.0 & - & - & 95.0 & -- \\
\hline Demarcation of the surgical site & - & 23.8 & 100.0 & 97.3 & 3.0 & 56.0 & 49.9 \\
\hline Confirmation of fasting & - & - & 45.0 & 96.9 & - & 70.9 & 36.7 \\
\hline Placement of the oximeter & 100.0 & 99.3 & - & - & 80.0 & 93.1 & 11.4 \\
\hline Operation of the oximeter & 100.0 & 99.1 & - & - & 80.0 & 93.2 & 11.3 \\
\hline Confirmation of patient allergies & 0.0 & 14.6 & 100.0 & 90.6 & 94.0 & 59.8 & 48.4 \\
\hline Checking the patient's airway & 0.0 & 10.0 & 100.0 & - & 69.0 & 44.7 & 47.8 \\
\hline Verification of bleeding risk and blood reserve & 0.0 & 15.0 & 95.0 & 91.1 & 72.0 & 54.6 & 44.2 \\
\hline Instrumental/material verification & 100.0 & - & 100.0 & - & - & 100.0 & 0.0 \\
\hline Checking the anesthesia material & 100.0 & - & 100.0 & - & - & 100.0 & 0.0 \\
\hline Verification of material sterilization validity & 0.0 & - & 100.0 & - & - & 50.0 & 70.7 \\
\hline Checking the aspirator & 0.0 & - & 95.0 & - & - & 95.0 & 67.2 \\
\hline Heater check & 0.0 & - & 100.0 & - & - & 100.0 & 70.7 \\
\hline Surgical team in the room & 0.0 & - & - & - & - & 0.0 & -- \\
\hline Nursing staff in room & 100.0 & - & - & - & - & 100.0 & -- \\
\hline
\end{tabular}


Table 2 - Distribution of the relative frequency, mean and standard deviation of the check of the Time Out items of the Surgical Safety Checklist

\begin{tabular}{|c|c|c|c|c|c|c|c|}
\hline \multirow{2}{*}{ Items } & \multicolumn{5}{|c|}{ Articles } & \multirow{2}{*}{ Mean (\%) } & \multirow{2}{*}{$\begin{array}{l}\text { Standard } \\
\text { Deviation }\end{array}$} \\
\hline & $1(\%)$ & $2(\%)$ & $3(\%)$ & $4(\%)$ & $5(\%)$ & & \\
\hline Confirmation of procedure & - & 76.1 & 100.0 & 85.2 & 84.0 & 86.3 & 9.9 \\
\hline Instrument count & 0 & 70.2 & 0 & 84.8 & 67.0 & 44.4 & 41.1 \\
\hline Compressor count & 0 & - & - & 92.2 & - & 46.1 & 65.2 \\
\hline Gassing count & 0 & - & - & 79.4 & - & 39.7 & 56.1 \\
\hline Identification of specimens & - & 98.8 & 100.0 & 87.9 & 62.0 & 87.2 & 17.6 \\
\hline Problems with equipments & - & 51.4 & - & - & 45.0 & 48.2 & 4.5 \\
\hline Anesthesia Sheet & - & - & 100.0 & 91.8 & - & 95.9 & 5.8 \\
\hline Review of special care in patient recovery & 0 & 79.2 & 100.0 & 0 & 68.0 & 49.4 & 46.6 \\
\hline Record of procedure & 100.0 & - & - & - & - & 100.0 & -- \\
\hline
\end{tabular}

Table 3 - Distribution of the relative frequency, mean and standard deviation of the check of the Sign Out items of the Surgical Safety Checklist

\begin{tabular}{|c|c|c|c|c|c|c|c|}
\hline \multirow{2}{*}{ Items } & \multicolumn{5}{|c|}{ Articles } & \multirow{2}{*}{ Mean (\%) } & \multirow{2}{*}{$\begin{array}{l}\text { Standard } \\
\text { Deviation }\end{array}$} \\
\hline & $1(\%)$ & $2(\%)$ & $3(\%)$ & $4(\%)$ & $5(\%)$ & & \\
\hline Confirmation of procedure & - & 76.1 & 100.0 & 85.2 & 84.0 & 86.3 & 9.9 \\
\hline Instrument count & 0 & 70.2 & 0 & 84.8 & 67.0 & 44.4 & 41.1 \\
\hline Compressor count & 0 & - & - & 92.2 & - & 46.1 & 65.2 \\
\hline Gassing count & 0 & - & - & 79.4 & - & 39.7 & 56.1 \\
\hline Identification of specimens & - & 98.8 & 100.0 & 87.9 & 62.0 & 87.2 & 17.6 \\
\hline Problems with equipments & - & 51.4 & - & - & 45.0 & 48.2 & 4.5 \\
\hline Anesthesia Sheet & - & - & 100.0 & 91.8 & - & 95.9 & 5.8 \\
\hline Review of special care in patient recovery & 0 & 79.2 & 100.0 & 0 & 68.0 & 49.4 & 46.6 \\
\hline Record of procedure & 100.0 & - & - & - & - & 100.0 & -- \\
\hline
\end{tabular}

\section{Discussion}

This study presents as limitation possible bias related to the selection of published articles, which cannot be measured, considering the languages defined for the screening of potential articles for analysis, as well as for the databases selected for search, which resulted in a sample of five national articles for review. Another aspect refers to the heterogeneity of check items in the lists, because they were adapted to each local reality, which made it impossible to calculate the average of filling certain security items.
The results evidenced the inadequate filling of surgical safety items in the checklist, which may be associated with the limited acceptance of the checklist by the surgical team professionals, in the operating room practice, in addition to revealing flaws in the procedures for implementing the surgical protocol surgical centers of Brazilian hospitals. The obligation to execute the list, the awareness of the team and the involvement of the team in the implementation of the procedure positively influence the quality of the pro- 
$\operatorname{cess}^{(20)}$. The imposition of the use increases the frequency of use of the instrument, on the other hand, the participation of the professionals in the implementation, especially in the adaptation of the list to the local reality, improves the quality of the filling ${ }^{(19)}$.

The use of the checklist promoted good levels of verification of aspects important for surgical safety, such as patient identification, with mean verification frequency lower than $90.0 \%$ in only one study, no sign in; and, in two studies, in time out. The high standard deviation is justified by the low conference in the first article. Emphasis is given to the importance of systematically conferring patient data on safety promotion by ensuring that there is no patient exchange and that surgery will be performed on the correct patient. The Brazilian Ministry of Health advocates the identification of all patients in health services, in order to prevent incidents related to the exchange of patients ${ }^{(8)}$. In Brazil, in 2014, 35.0\% of the hospital incidents were related to failures in patient identification and $2.0 \%$ corresponded to the care provided to the wrong patient ${ }^{(21)}$. The identification of the surgical patient should be confirmed with the patient, whenever possible ${ }^{(5,8)}$, however, in none of the studies was the manner in which this verification was performed.

No sign in, verification of consent was not satisfactory. Although three studies presented a frequency of checks greater than $90.0 \%$, one of them indicated nonconformity in all procedures and the first article demonstrated that the confirmation was not performed in any surgery, expressing a high standard deviation. The physician has a duty to provide patients with clear and adequate information, as well as to obtain their consent prior to any conduct, except in situations of imminent risk of death ${ }^{(22)}$, in order to guarantee transparency and quality to the doctor-patient.

Surgical teams were worried about the pulse oximeter test, an important test that indicates a decrease in the rate of hypoxemic events ${ }^{(23)}$, although two articles did not address this item. Considering that the understanding of the purpose of the checks increases the importance extended to each item and improves the adherence of the professionals ${ }^{(19)}$, it seems that in the studies that did not address this element, the team was not sufficiently aware of its benefits. Among the monitoring equipment, the oximeter is particularly important because it allows the early identification of respiratory events, one of the main incidents related to mortality in anesthesia ${ }^{(5)}$.

The pre-anesthetic evaluation refers to the investigation of the clinical and historical status of the patient and investigation of the fasting, the airway and known allergies, supporting the assistance planning. The team should also be aware of the risk of large blood loss to be effectively prepared, with venous access and available fluids, for possible complications ${ }^{(5)}$. These sign in items were poorly filled, which indicates inattention to this security measure and reinforces team misinformation. The empowerment of professionals, demonstrated by the recognition of the need to conference all items, increases the completeness of the checklist ${ }^{(19-20)}$.

Despite the high frequency of confirmation of the procedure and the surgical site in the sign in (95.0\%), only one study cited the verification of these items and mentioned that in only half of the surgeries verification occurred verbally, in the other half, it was not observed verbal expression, although the corresponding item is checked in the instrument ${ }^{(17)}$. The same occurred with the verification of the equipment and anesthesia materials, instrumentation, material validity, vacuum and heater check, procedure confirmation, dispersal plate placement of the electric scalpel and risk related to surgical positioning, which had a check of $100.0 \%$ in this same study, however, there was no significant adherence, since items were checked in the checklist, without actually being applied verbally. This information hinders the reliability of the calculated mean and the generalization of the results, however, only in this study was the nonverbal verification of the items in the checklist explained, making it impossible to compare the other articles analyzed.

Although the confirmation of the surgical site was not confirmed in only one article and the verifi- 
cation of site demarcation had low check (56.0\%), at time out, confirmation of the site to be operated was high (98.4\%). However, the calculation was based on data from two studies. In addition, in the third article, only $5.0 \%$ of the verifications were carried out verbally, and the fourth one mentioned that in $8.2 \%$ of operations the site was not demarcated. The demarcation of the surgical site, especially in situations involving laterality, multiple structures or levels, is fundamental for the prevention of operation in the wrong place ${ }^{(5)}$. Surgeries at wrong surgical sites are a challenge to be faced ${ }^{(18)}$.

The use of the checklist makes the communicative process more effective in the operating rooms ${ }^{(10,16)}$, which is essential in the safety culture. Especially, surgical pause is a time for discussion about serious events and operative planning ${ }^{(8)}$. However, the communication between the teams of the analyzed articles proved to be ineffective, demonstrated by the low frequency of checking the presentation of the team and the verification of possible critical events in the time out. The verification of critical events by nursing had a higher filling frequency, although not satisfactory.

At time out, the frequency of verification of prophylactic antibiotic administration prior to surgical incision was greater than $89.0 \%$ in three studies, demonstrating concern of the teams with the prevention of surgical site infection. Despite this, in one of the studies, there was no confirmation of this item in any surgery, which resulted in high standard deviation. It is pointed out that the studies did not mention the indication of antibiotic prophylaxis for observed surgeries, thus, the inclusion of procedures, in which it is not necessary to use the prophylactic antibiotic, may justify the reduced verification. In spite of this, the conference of all the elements is recommended in any situation, so that the information is passed on to all those present in the operating room ${ }^{(5)}$.

In the third step of the checklist, the low verification of the surgical instrument count, gauzes and compresses stands out. This count should begin at the time of surgery closure, in order to avoid inadvertent retention of materials within the patient ${ }^{(5)}$. The incidence of this event is underreported and is increasing, so good practices should be reviewed for preventive measures such as careful counting of surgical material $^{(24)}$

The identification of the specimens had an average of $87.2 \%$ and a standard deviation of 17.6. Greater importance should be given to this item, since identification problems can lead to errors of diagnosis and delays in treatment. Half of the errors of laboratory specimens are related to problems in their identification ${ }^{(5)}$. There is a need for better knowledge of the wrongs of incorrect labeling and well defined work processes, with the correct identification of the person responsible for this task, in order to optimize this data.

The identification of problems with equipment during surgery also presented deficient checking. One of the possible reasons is that the professional of the team considers that it is not within their competence to solve technical-operational problems. However, the identification of equipment malfunctions by the team is important, in order to avoid delays in the procedures, besides facilitating the search for the immediate solution of the problem ${ }^{(5)}$.

Low revision of the care review item needed in patient recovery evidence of discontinuity of care provided to the patient, since the surgical-anesthetic procedure and in situations of complications in the course of the process are closely related to the care that needs to be taken care of in the room recovery -anesthetic. The postoperative ward plan should be reviewed by the surgeon, anesthesiologist and nursing team, in order to recover the patient's recovery capacity, in order to efficiently and appropriately transfer critical evaluation ${ }^{(5)}$.

Comparing with the three stages of the checklist, it is observed a greater commitment to a first stage, in which $48.0 \%$ of the items obtained an average of $90.0 \%$, against $38.0 \%$ in the second, and $2.0 \%$, in the third step. Overall demand, the average filling of 
all elements of the Brazilian surgical teams was low, since $28.0 \%$ of the items had a check frequency lower than $50.0 \%$.

In addition, the low frequency of screening, unappropriated practices contrary to the World Health Organization were mentioned, such as non-verbal list application and postponement of checks. In the second study, $80.0 \%$ of the instrumental counts were after the patient left, and in the third study, $45.0 \%$ of the times the time out was performed, it was applied after the surgical incision.

Verbal checking is aimed at promoting teamwork and the exchange of information among professionals ${ }^{(5)}$. Inadequacy of the process suggests, again communication problem among professionals. The delay in the list makes the process pointless, for missing an opportunity to identify risks to the patients, by checking the safety features before proceeding with surgery.

Other inconsistencies were presented. In the fourth study, in spite of the good verification of the surgical site, in $8.2 \%$ of the cases that involved laterality, the surgical site was not demarcated, and on the fifth article, which list was applied in $60.8 \%$ of the surgeries, in only $3.5 \%$ of cases the instrument was completely filled.

It is possible that the professionals' conceptions about the importance of the items on the list influence their use. The items most directly related to the activities of the nursing professionals had a higher average of completion, possibly due to the fact that the checking process leader be, in most times, a member of the nursing team, in contrary, lower adherence to the process is observed by surgeons ${ }^{(16)}$.

The large variation of the checking frequency of each item and the low gauging of most of them show inconsistency and low quality in the surgical safety process. Therefore, the importance of continuing education to disseminate safety practices is highlighted $^{(20)}$. The establishment of a safety culture involves organizational management, active leadership, effective communication, teamwork, individual be- liefs, as well as a non-punitive culture, learning from mistakes, considered an area to be optimized ${ }^{(25)}$.

It is worth mentioning that the results of the Brazilian studies analyzed corroborate findings from research in developed countries, such as Switzerland and the United Kingdom ${ }^{(26-27)}$, reflecting that nonconformities in the surgical safety procedure do not relate exclusively to the limitation of resources or infrastructure of the surgical centers.

Studies that identify factors related to adherence to the checklist and that evaluate effective implementation methods are essential for a better understanding of the phenomenon and an urgent advance of the global challenge within the country.

\section{Conclusion}

The frequency of checking the items of the Surgical Safety Check List by surgical teams in Brazilian hospitals was unsatisfactory, which suggests a low adherence to the surgical safety process, evidencing the need for improvements based on the safety culture of the surgical patient.

\section{Collaborations}

Almeida RE contributed with project design, data collection, analysis, interpretation, and article writing. Rodrigues MCS collaborated with project conception, article writing, relevant critical review of the intellectual content and approval of the final version to be published.

\section{References}

1. Ministério da Saúde (BR). Agência Nacional de Vigilância Sanitária. Documento de referência para o Programa Nacional de Segurança do Paciente. Brasília: Ministério da Saúde; 2014.

2. Trindade L, Lage MJ. A perspectiva histórica e principais desenvolvimentos da segurança do paciente. In: Sousa P, Mendes W. Segurança do paciente: conhecendo os riscos nas organizações de saúde. Rio de Janeiro: Fiocruz; 2014. p.39-56. 
3. Anderson O, Davis R, Hanna GB, Vincent CA. Surgical adverse events: a systematic review. Am J Surg. 2013; 206(2):253-62. doi: http://dx.doi. or/10.1016/j.amjsurg.2012.11.009

4. Mendes W, Pavão ALB, Martins M, Moura MLO, Travassos C. Características de eventos adversos evitáveis em hospitais do Rio de Janeiro. Rev Assoc Méd Bras. 2013; 59(5):421-8. doi: http:// dx.doi.org/10.1016/j.ramb.2013.03.002

5. Ministério da Saúde (BR). Agência Nacional de Vigilância Sanitária. Organização Mundial da Saúde. Segundo desafio global para a segurança do paciente. Cirurgias seguras salvam vidas. Rio de Janeiro: Organização Pan-Americana da Saúde; 2009.

6. Ministério da Saúde (BR). Portaria no 529, de $1^{\text {o }}$ de abril de 2013. Institui o programa nacional de segurança do paciente (PNSP). Brasília: Ministério da Saúde; 2013.

7. Ministério da Saúde (BR). Agência Nacional de Vigilância Sanitária. Resolução RDC nํ36, de 25 de julho de 2013. Institui ações para a segurança do paciente em serviços de saúde e dá outras providências. Brasília: Ministério da Saúde; 2013.

8. Ministério da Saúde (BR). Agência Nacional de Vigilância Sanitária. Portaria no 2095, de 24 de setembro de 2013. Aprova os protocolos básicos de segurança do paciente. Brasília: Ministério da Saúde; 2013.

9. Haynes AB, Edmondson L, Lipsitz SR, Molina G, Neville BA, Singer SJ, et al. Mortality trends after a voluntary checklist based surgical safety collaborative. Ann Surg. 2017; 266(6):923-9. doi: http:// dx.doi.org/10.1097/SLA.0000000000002249

10. Pancieri AP, Santos BP, Avila MAG, Braga EM. Safe surgery checklist: analysis of the safety and communication of teams from a teaching hospital. Rev Gaúcha Enferm. 2013;34(1):71-8. doi: http://dx. doi.org/10.1590/S1983-14472013000100009

11. Pancieri AP, Carvalho RD, Braga E. Aplicação do checklist para cirurgia segura: relato de experiência. Rev SOBECC. 2014; 1(19):26-33. doi: http://dx.doi.org/10.4322/sobecc.2014.006
12. Mendes KDS, Silveira RCCP, Galvão CM. Integrative literature review: a research method to incorporate evidence in health care and nursing. Texto Contexto Enferm. 2018; 17(4):75864. doi: http://dx.doi.org/10.1590/S010407072008000400018

13. Moher D, Liberati A, Tetzlaff J, Altman DG. Reprintpreferred reporting items for systematic reviews and meta-analyses: the PRISMA statement. Phys Ther. 2009; 89(9):873-80. doi: http://dx.doi. org/10.7326/0003-4819-151-4-20090818000135

14. Karino ME, Felli VEA. Enfermagem baseada em evidências: avanços e inovações em revisões sistemáticas. Cienc Cuid Saúde. 2012; 11(5):115. doi: http://doi.org/10.4025/cienccuidsaude. v10i5.17048

15. Giannattasio MB, Taniguchi FP. Avaliação da segurança do paciente em cirurgia cardíaca de um hospital público. Rev SOBECC. 2016; 2(3):125-31.doi:https://doi.org/10.5327/Z14144425201600030002

16. Santana HT, De Freitas MR, Ferraz EM. WHO Safety surgical checklist implementation evaluation in public hospitals in the Brazilian Federal District. J Infect Public Health. 2016; 9(5):586-99. doi: http://dx.doi.org/10.1016/j.jiph.2015.12.019

17. Maziero ECS, Silva ABC, Mantovani MF, Cruz EDA. Adherence to the use of the surgical checklist for patient safety. Rev Gaúcha Enferm. 2015;36(4):1420.doi:http://dx.doi.org/10.1590/19831447.2015.04.53716

18. Amaya MR, Maziero ECS, Grittem L, Cruz EDA. Analysis of the registration and content of surgical safety checklist. Esc Anna Nery. 2015; 19(2):24651.doi:http://dx.doi.org/10.5935/14148145.20150032

19. Freitas MRD, Antunes AG, Lopes BNA, Fernandes FDC, Monte LDC, Gama ZADS. Avaliação da adesão ao checklist de cirurgia segura da OMS em cirurgias urológicas e ginecológicas, em dois hospitais de ensino de Natal, Rio Grande do Norte, Brasil. Cad Saúde Pública. 2014; 30(1):137-48.doi: http://dx.doi.org/10.1590/0102-311X00184612 
20. Carmo TG, CriadoJVN, Dias BF. The implementation process of the safe surgery protocolo. Rev Cubana Enferm [Internet.] 2017 [cited 2018 Jul. 22]; 33(1). Available from: http://revenfermeria.sld. cu/index.php/enf/article/view/1028/240

21. Ministério da Saúde (BR). Agência Nacional de Vigilância Sanitária. Boletim Informativo Segurança do Paciente e Qualidade em Serviços de Saúde - Incidentes Relacionados à Assistência à Saúde-2014. Brasília: Ministério da Saúde; 2015.

22. Conselho Federal de Medicina. Resolução nํ1931, de 17 de setembro de 2009. Aprova o Código de Ética Médica. Brasília: Conselho Federal de Medicina; 2010.

23. Kim RY, Kwakye G, Kwok AC, Baltaga R, Ciobanu G, Merry AF, Haynes AB. Sustainability and longterm effectiveness of the WHO Surgical Safety Checklist combined with pulse oximetry in a resource-limited setting: two-year update from Moldova. JAMA Surg. 2015; 150(5):473-9. doi: http://dx.doi.org/10.1001/jamasurg.2014.3848
24. Silva SM, Sousa JB. Gossipiboma pós operação abdominal é situação clínica desafiadora e sério problema médico legal. Arq Bras Cir Dig. 2013; 26(2):140-3. doi: http://dx.doi.org/10.1590/ S0102-67202013000200015

25. Tavares APM, Moura ECC, Avelino FVSD, Lopes VCA, Nogueira LT. Patient safety culture from the perspective of the nursing team. Rev Rene. 2018; 19:e3152. doi: http://dx.doi.gor/10.15253/21756783.2018193152

26. Cullati S, Le Du S, Rae AC, Micallef M, Khabiri E, Ourahmoune A, et al. Is the Surgical Safety Checklist successfully conducted? An observational study of social interactions in the operating rooms of a tertiary hospital. BMJ Qual Saf. 2013; 22(8):639-46.doi: http://dx.doi. org/10.1136/bmjqs-2012-001634

27. Pickering SP, Robertson ER, Griffin D, Hadi M, Morgan LT, Catchpole KC, et al. Compliance and use of the World Health Organization checklist in UK operating theatres. Br J Surg. 2013; 100(12):166470. doi: http://dx.doi.org/10.1002/bjs.9305 